\title{
Determinates of factors influencing job satisfaction and organizational loyalty
}

\section{Bui Nhat Vuonga ${ }^{a}$, Dao Duy Tung ${ }^{\mathrm{b}}$, Hasanuzzaman Tushar ${ }^{\mathrm{c}}$, Tran Nhu Quan ${ }^{\mathrm{d}}$ and Ha Nam Khanh Giao}

${ }^{a}$ Faculty of Air Transport, Vietnam Aviation Academy, Vietnam

${ }^{b}$ Faculty of Business Administration, Tay Do University, Vietnam

${ }^{c}$ College of Business Administration, International University of Business Agriculture and Technology, Bangladesh

${ }^{d}$ School of Business, International University Ho Chi Minh City, Vietnam Vietnam National University, Ho Chi Minh City, Vietnam

\section{H R O N I C L E}

\begin{tabular}{l} 
Article history: \\
Received: June 27, 2020 \\
Received in revised format: \\
August 102020 \\
Accepted: August 10, 2020 \\
Available online: \\
August 10, 2020 \\
\hline Keywords: \\
Income \\
Quality of medical examination \\
and treatment \\
Hospital resources \\
Job satisfaction \\
Organizational loyalty
\end{tabular}

\section{A B S T R A C T}

Human resources in the medical sector play a very important role in public service activities to perform tasks as prescribed by law to serve the interests of the people and society. In this way, the service of medical doctors also has a direct effect on the public services and healthcare services of Vietnam. This research analyzes factors affecting doctors' satisfaction and loyalty from a survey of 228 doctors working in public hospitals in Vietnam. The study was conducted using both qualitative and quantitative tools to examine the hypotheses of the survey. Cronbach's Alpha analysis, Explanatory Factor Analysis (EFA) analysis and Structural Equation Modeling (SEM) were employed to test the relationship among the factors in the research model. The results indicated that the influential factors on the satisfaction of a doctor's job include the following, listed in diminishing importance order: (1) Income, (2) Relationship with colleagues, (3) Quality of medical examination and treatment, (4) Hospital resources, (5) Autonomy at work, (6) Training and promotion opportunities. Besides, when doctors are satisfied with their job, they tend to be loyal to the organization. The study proposes several policy implications for medical sector managers to increase the doctors' satisfaction and loyalty in public health services.

\section{Introduction}

A good public healthcare necessitates the development of the medical system in which the team of doctors plays a crucial role. However, in Vietnam, it seems that doctors have not been given enough attention commensurate with their importance to society. Hazardous working conditions and high work pressure requires medical doctors to make continuous knowledge updates with no or few professional errors tolerated. In addition, the modern lifestyle creating new and more dangerous diseases that pose a great threat to human health and imposes surging demands for public healthcare. Because medical doctors play a crucial role in public healthcare as the ones who carry out direct diagnosis and treatment of patients, the research of human resource management on teams of doctors is extremely necessary for leaders and managers, especially the aspect of job satisfaction and loyalty to the physician organizations. Despite many incentives from the governmental policies to keep talented employees in public sectors, there are human capital flights in public hospitals. Skilled doctors and specialists are leaving public hospitals and community healthcare centers with increasing rates. Retention of these physicians, especially doctors with good skills and in-depth expertise, to maintain and develop human resources in service of medical examination and treatment for people is one of the important orientations of the Vietnam Ministry of Health. Because of the importance of human resources in the public health sector, the study of the factors affecting job satisfaction and organizational loyalty of medical doctors is more meaningful than ever. Job satisfaction and organizational loyalty are the typical research issues that have been studied in many fields and professionals in Vietnam, however, to the best review of the authors, this research is a pioneer study that clarifies the job satisfaction and organizational loyalty of medical doctors in Vietnam public health-care sector.

\footnotetext{
* Corresponding author.

E-mail address: nhatvuonga1@gmail.com (B. N. Vuong) 


\section{Theoretical background}

\subsection{The concept of job satisfaction}

According to Mitchell and Lason (1987), job satisfaction is one of the important issues in organizational behavior that has been studied by many scholars worldwide. Locke and Latham (1990) suggest that job satisfaction is an interesting or positive emotion toward a job based on personal working experiences and evaluations. In this way, job satisfaction is an attitude resulting from how employees perceive their work to deliver the value is considered important to the organization and themselves. According to Spector (1997), job satisfaction is the way employees feel about the job and the various aspects of the job. It is the extent to which employees like (satisfied with) or dislike (not satisfied with) their jobs. Robbins and Judge (2018) state that job satisfaction refers to an individual's overall attitude toward his or her job. A person with high job satisfaction would keep a positive attitude toward his job while a person who is dissatisfied with himself or his job would keep a negative attitude about his job. According to Dessler (2019), job satisfaction is an emotional response to different aspects of work. In another view, Schmidt (2007) proposes that job satisfaction is a state in which employees have a clear and effective direction for work in the organization. Thus, job satisfaction is defined in many ways that are not universally agreed researchers from different perspectives, schools, and fields. According to the authors' approach, job satisfaction is the employees' ability to show their full potentials, qualifications, and strengths at work accompanied by the comfortable and satisfying feeling with the jobs they are doing. The employees also feel satisfied when they receive compensation deserving of their contributions.

\subsection{The concept of organizational loyalty}

In the business environment today, successful companies heavily rely on the efforts of their talented employees. This fact is especially true in industries such as high technology, biotechnology, and medical healthcare (Aityan \& Gupta, 2011). Over the years, there have been many definitions of loyalty from different scholars and organizations. Are hard-working and industrious employees who always concerned about the company's benefits considered as loyal? It is not always easy to define employee loyalty. Lawrence (1958) researches the relationship between corporations and its employees to emphasize that employee loyalty is reflected when the employees act in line with managerial guidance. Many years ago, the definition of organizational loyalty was widely understood as an employee who felt attached to the organization (Buchanan, 1974). Loyalty basically belongs to the emotional category. Loyal people are those who always stand shoulder to shoulder with the organization even in times of absolute difficulty and they are not those who ignore or flee in distress. Loyalty helps to build trust between people and is an essential element in creating values of life. Organizational loyalty represents the virtue when a person is willing to contribute or sacrifice his or her personal interests for strengthening abound to an organization. Business organizations propose that the best form of loyalty is when both the company and its employees have mutual benefits. There are many different definitions and views of loyalty. To regain focus, the authors take the perspective to define organizational loyalty as the employees' intention or desire to maintain the membership of an organization, to participate enthusiastically, and to work hard for the organization's goals.

\subsection{Benefits of building and maintaining employee loyalty}

Employees are an extremely important resource for any company. According to Cooil et al. (2007), companies with more loyal employees will have more competitive advantages, higher survival rates, and higher success rates than companies with fewer loyal employees. Talented and loyal employees are always an asset to the company. Reserving talented and loyal employees are the key to the company's success. The added-benefits of building and maintaining employee loyalty, from the view of managers, are minimizing costs, retaining loyal customers, and stabilizing company operations. Maintaining loyalty among employees, customers, and shareholders would bring in more profit to the companies. So, companies can facilitate the implementation of their strategic plans if they have developed and maintained a loyal staff with high productivity. In the past, most employees spent the majority of their time working for a single company. So, having a job means having a commitment to this life so that everyone would be hired and retired from the same company. Employees will look at job safety in exchange for loyalty and hard work and employers are also more loyal to employees. The situation has changed a lot nowadays, loyal employees will contribute to the growth and sustainability of the company by reducing financial distress, saving the cost of recruiting and training new employees, providing training courses for junior employees as well as winning new potential customers for the companies. However, employee loyalty is not something that administrators and managers can easily obtain because loyalty is not a one-time job. It requires employers to regularly build mutual relationships between managers, employees, and companies. Therefore, administrators and employers need to be more active and proactive in recognizing the benefits of understanding, managing, and increasing employee loyalty.

\section{Hypothesis Development}

From the theoretical background and related studies, the authors investigate and select factors influencing employee satisfaction and organizational loyalty by using components in empirical studies (e.g., Chang et al., 2010; Friedberg et al., 2014; Vuong, Dao Duy, et al., 2020). These empirical studies also document the satisfaction and loyalty of doctors in hospitals, which subsequently becomes a solid theoretical basis for the authors to apply suitable models in accordance with the current conditions of the Vietnam medical health-care sector. 
The authors adjust and supplements to some observation variables in contemporary research models on employee satisfaction and loyalty to reflect the actual conditions in Vietnam. As a result, the author proposed an initial research model including 06 factors: (1) Quality of medical examination and treatment, (2) Electronic medical records, (3) Autonomy at work, (4) Income, (5) Hospital resources, (6) Relationship with fellow doctors. Additionally, based on qualitative research results, two-thirds of the discussion panel members also agree that the six factors that the author mentioned during the discussion are quite adequate in researching the organizational loyalty of medical doctors. Besides, the discussion group agrees to include one additional factor that has been assessed to have a significant effect on the doctor's satisfaction, the "Training and advancement opportunities", in this research in Vietnam. Th model is shown in Fig. 1.

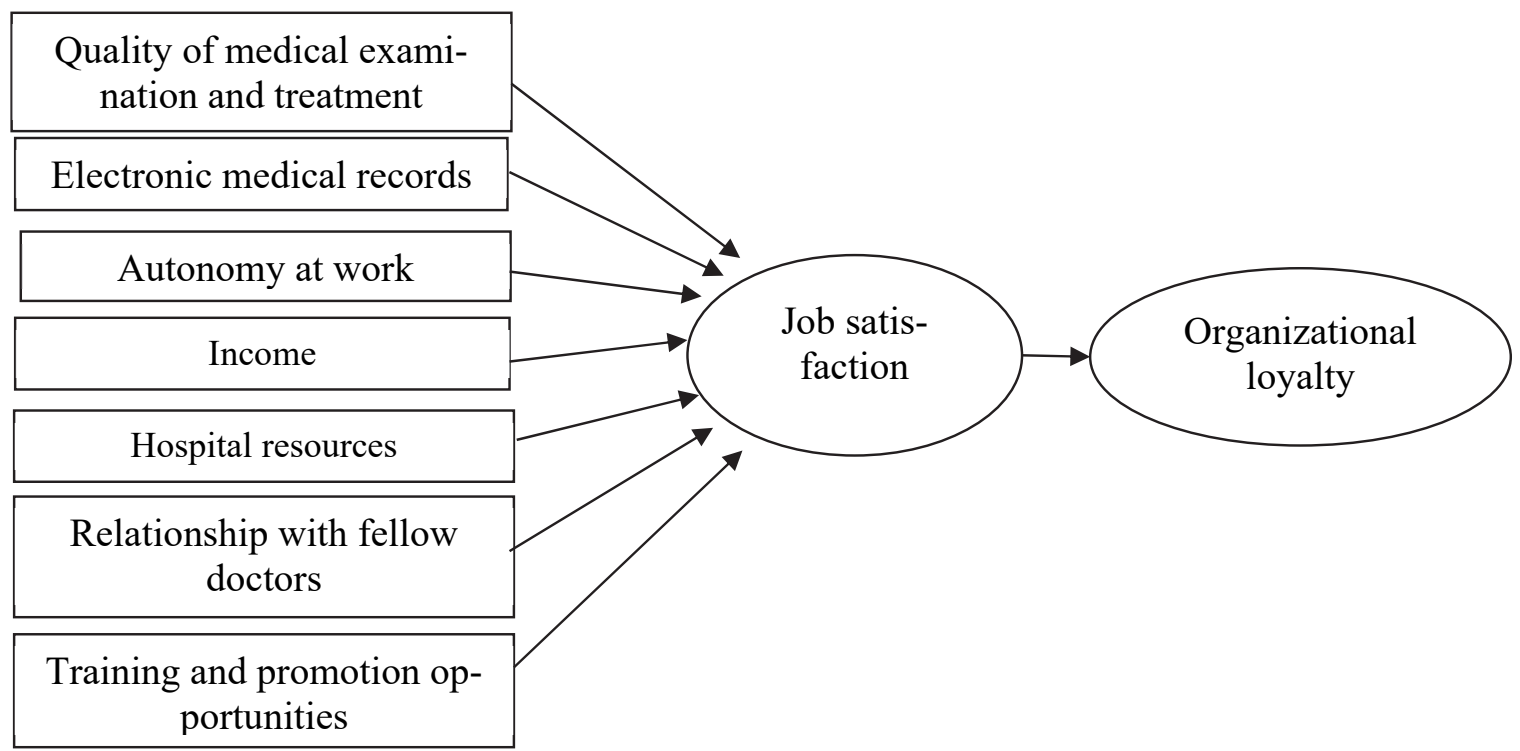

Fig. 1. Research model

\subsection{The quality of medical examination and treatment}

The quality of medical examination and treatment is the level of expected health improvement delivered to the community and individuals by health-care services in accordance with the current professional knowledge. Quality of medical examination and treatment is the attributes of healthcare activities that increase the patient's chance of getting good health, the chance of avoiding harmful pitfalls, and chances of having good experience with the healthcare system. The quality of healthcare is achieved when patients receive the services, they need without unnecessary humanitarian risks. To achieve quality medical care, hospitals need not only good doctors but also a good system of machines, equipment, and services. The quality of medical examination and treatment is not only influenced by the doctor who directly examines patients but also from other colleagues in the hospital. According to the research of Friedberg et al. (2014), the quality of medical examination and treatment affects job satisfaction of medical doctors. Therefore, the authors propose hypothesis $\mathrm{H} 1$ as follows:

\section{$H_{1}$ : The quality of health examination and treatment positively affects the satisfaction of doctors in public hospitals.}

\subsection{Electronic medical records}

Electronic medical records are computer software that includes functions for storing patient demographic data, pre-pathology, medicine usage, and subclinical results. The software can also store drug information and treatment regimens, which makes it convenient for doctors to command medication. Electronic medical records may be part of a hospital management software system. In the process of outpatient medical examination and treatment, electronic medical records are useful for medical doctors in prescribing drugs, such as giving the names of medicines and active ingredients, specifying the interaction of drugs with each other, and issuing a warning of the drugs that are not in the treatment regimen of the hospital. Electronic medical records also facilitate the process of issuing subclinical orders, such as showing the tests and image diagnostics that the hospital is capable of doing and highlight the sections that are not in the coverage group of healthcare insurance. In addition, electronic medical records can estimate the treatment fee that the patient has pay to the hospital after accounting for insurance coverage. During the course of treatment at the hospital, electronic medical records can help the doctors search for data about the patient's previous illness easily without having to look through old paper records. In serious illness cases that necessitate close monitoring, devices attached to patients such as ventilators will be connected to the applications on the doctor's phone. Any abnormalities of the patients will be reported directly to the doctor at anytime and anywhere. According to the research results of Friedberg et al. (2014), the factor of electronic medical records affects job satisfaction of medical doctors. Therefore, we introduce the hypothesis $\mathrm{H} 2$ as follows:

\section{$\mathrm{H}_{2}$ : Electronic medical records positively impact the job satisfaction of doctors in public hospitals.}




\subsection{Autonomy at work}

Autonomy at work is the degree of freedom or the degree of control that employees have been granted in the daily working schedule. Autonomy at work can be an important factor in reducing stress and improving the quality of work because it encourages employees to feel efficient, accountable, and trusted by others in the organization. Autonomy in the medical professional is the capability of the employees to be proactive in making treatment decisions, selecting co-treatment colleagues, analyzing and interfering with management decisions when necessary, and taking initiatives in selecting working hours and a working schedule that is suitable to employees' role. Following the researches of Kim et al. (2018) and Zia ul et al. (2016) indicates that autonomy at work affects job satisfaction of employees. Thus, we have the hypothesis H3 as follows:

$H_{3}$ : Autonomy at work positively affects job satisfaction of doctors in public hospitals.

\subsection{Income}

Income, including both salary and bonus, is determined as a factor affecting employee loyalty. The incentive core for people to act is centered around using money as the encouragement and attraction to work. Income is the amount of compensation an employee earns from their monthly and regular working schedule. This income also includes any recurring and non-recurring bonuses, commissions, and other monetary benefits directly arising from the performance of the current main job. This amount, however, does not include other incomes when employees do other jobs outside their main company. Salary may have different names such as labor, labor income, etc. based on previous research results (e.g., Vuong, et al., 2020; Vuong \& Suntrayuth, 2020), the income factor affects job satisfaction. Thus, we suggest the hypothesis $\mathrm{H}_{4}$ as follows:

$\mathrm{H}_{4}$ : Income has a positive impact on job satisfaction of medical doctors in public hospitals.

\subsection{Hospital resources}

Resources for healthcare activities include human capital and physical capital. Human resources are a very important source of human capital in which education and training are seen as the decisive tools for adjusting knowledge and skills. Unlike physical capital, knowledge does not wear out during use. However, skills will become obsolete over time with the advancement of new equipment and technology. Therefore, continuing education and training is necessary to update current skills in line with the advancement of new technology and knowledge. Satisfaction to hospital resources is the contentment with the quality of the people and facilities for clinical practice. The research results of Wada et al. (2009) show that the factor of hospital resources affects job satisfaction. Therefore, we introduce the hypothesis H5 as follows:

$H_{5}$ : Hospital resources positively influence the job satisfaction of medical doctors in public hospitals.

\subsection{Relationship with fellow doctors}

Relationships with colleagues and fellow doctors are combinations of relationships between individuals within the organization. This kind of relationship is one of the important factors affecting employee engagement and attachment to the organization. In clinical practice, collaboration and cooperation among medical doctors are extremely important. In serious situations, physicians must gather to provide expert advice for the best examination and treatment of patients. Young physicians desperately need experience sharing and mentorship from senior physicians to avoid professional errors. In addition, medical doctors often must stick with hospital duties. When a doctor needs extra time to deal with a specific problem, other doctors in the department can arrange help on duty instead. The research results of Vuong and Suntrayuth (2020) have demonstrated that the relationship with fellow doctors affects the job satisfaction of medical doctors. This point leads to the hypothesis H6 as follows:

\section{$H_{6}:$ The relationship with fellow doctors is positively affecting the job satisfaction of medical doctors in public hospitals.}

\subsection{Training and promotion opportunities}

Training is the process of learning certain skills to perform a job well. Promotion is the advancement to a higher position of greater importance in an organization. In this research, training is considered as courses that provide or update contemporary skills and professional knowledge for medical doctors. Through training, medical doctors' skills are enhanced, job performance is facilitated and new opportunities for doctors' advancement are expanded. Therefore, progressive medical doctors all want to work in an environment with many learning opportunities to hone their knowledge and skills. The research results of Vuong, Dao Duy, et al. (2020) demonstrate that the training and promotion opportunities factor affects employee loyalty to the organization. From this observation, we recommend the hypothesis H7 as follows:

$H_{7}$ : Training and promotion opportunities have a positive impact on job satisfaction of medical doctors in public hospitals.

\subsection{Job satisfaction and organizational loyalty of medical doctors}

The level of job satisfaction can affect the employee retention rate when the employees make decisions to leave or stay with the organization based on how satisfied they feel at work. The authors argue that to improve employee loyalty to the organization, it is necessary to satisfy employee demands. The study of Chang et al. (2010) demonstrates the correlation between job satisfaction and employee loyalty to organizations in the public sector. Thus, we propose the hypothesis H8 as follows:

$H_{8}:$ Job satisfaction positively impacts the loyalty to the organization of medical doctors in public hospitals. 


\section{Research methodology}

The study is conducted using both qualitative research and quantitative research. Qualitative research is employed to verify the appropriateness of the measurement scales used to the current conditions of the healthcare sector in Vietnam. At the same time, qualitative research helps to evaluate the use of terminology in the questionnaire and improve concept clarification of questions before the official survey. Qualitative research was conducted by the group discussion method. The author conducted a group discussion by inviting 10 medical doctors who are working in public hospitals. The purpose of this group discussion is to explore research ideas, collect supplemental information, adjust the questions, and develop an official questionnaire to conduct quantitative surveys. The results of the group discussion demonstrate that the participants understand the content of the organizational loyalty of medical doctors in public hospitals. The participants all agree that the organizational loyalty of medical doctors is becoming increasingly important in maintaining and developing human resource quality that establishes the stability and advancement of the healthcare sector in Vietnam. Besides, more than two-thirds of the discussion group members also believe that the six factors mentioned by the authors are adequate to study the job satisfaction and organizational loyalty of medical doctors in public hospitals. In addition, the discussion group suggests adding one more factor that was assessed to impose a significant effect on the doctor's loyalty, the "Training and advancement opportunities". Based on the comments, the survey questionnaire is developed. After the adjustment of language presentation, the official questionnaire is used for subsequent quantitative research. Preliminary quantitative research was conducted by surveying 50 medical doctors working in public hospitals. The purpose of this pilot study is to evaluate the content and presentation of statements in the questionnaires to complete the official measurement scales that will be sent to broader research participants. The important task of this pilot study is to assess whether the respondents understand the questions or not by checking the level of verbal and grammatical compatibility in the survey questions to ensure consistency, improve clarity and avoid confusion for respondents. The reliability of observed variables is measured with a Likert-5 scale (1- Strongly Disagree, 2- Disagree, 3- Disagree, 4- Agree, 5- Strongly Agree) to eliminate inappropriate variables and prepare the official questionnaire to send to broader participants. The full-scale official quantitative research has been conducted by surveying 230 medical doctors who are working in public hospitals in Vietnam. The authors compile statistics based on information obtained from the survey results. This study uses SPPSS 20 and AMOS 20 software to check the adaptability and appropriateness of the proposed models and the hypothesis introduced by the authors.

\section{Research results}

This research has been conducted on 230 medical doctors working in public hospitals in Vietnam. Among 230 responses, there are 2 responses deemed to be invalid because of insufficient answers or false choices. Consequently, there are 228 valid responses accounting for $99.13 \%$ distributed questionnaires.

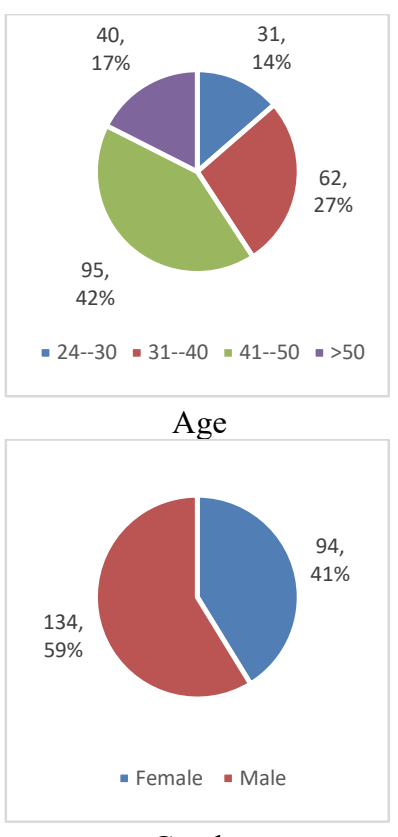

Gender

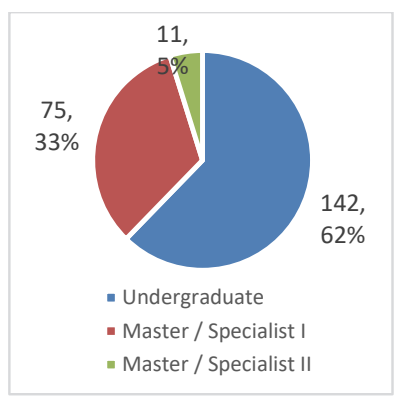

Education

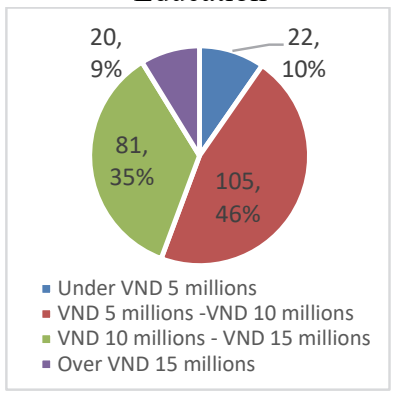

Income

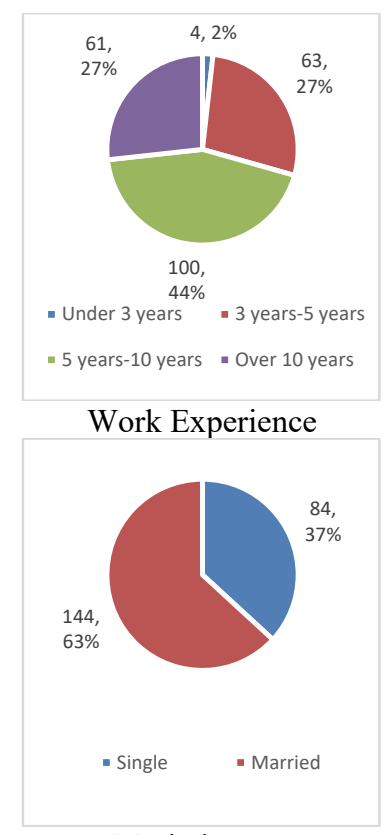

Marital status

Fig. 2. Personal characteristics of the participants

After the initial Cronbach's alpha analysis, EMR2 and AW4 were excluded because the correlations with the total variability were less than 0.3 (Giao, Vuong, Huan, et al., 2020). Subsequent tests indicated that the remaining measurement scales had high Cronbach's Alpha coefficients $(>0.7)$ with the correlation coefficient between items and total variability greater than 0.3 (Table 1). Therefore, all variables in this study achieved high reliability. 
Table 1

Results for EFA

\begin{tabular}{|c|c|c|c|c|}
\hline Constructs & CA & SC & Observed variables & Factor \\
\hline \multirow{5}{*}{$\begin{array}{l}\text { Relationship with fel- } \\
\text { low doctors }\end{array}$} & \multirow{5}{*}{0.897} & \multirow{5}{*}{0.685} & I have no difficulty sharing clinical situations with other doctors & 0.866 \\
\hline & & & My fellow doctors are professional supports & 0.83 \\
\hline & & & I live in harmony with my fellow doctors & 0.792 \\
\hline & & & My fellow doctors appreciated my consistent viewpoints in the treatment & 0.758 \\
\hline & & & Colleagues are an important source of personal support & 0.692 \\
\hline \multirow{5}{*}{$\begin{array}{l}\text { Training and promo- } \\
\text { tion opportunities }\end{array}$} & \multirow{5}{*}{0.904} & \multirow{5}{*}{0.725} & You explore your own chances of training and promotion & 0.84 \\
\hline & & & You are always encouraged to improve your professional qualifications & 0.823 \\
\hline & & & You have many promotion opportunities in the hospital & 0.813 \\
\hline & & & You attend many professional training courses & 0.795 \\
\hline & & & Fair promotion policy & 0.772 \\
\hline \multirow{5}{*}{ Hospital resources } & \multirow{5}{*}{0.843} & \multirow{5}{*}{0.615} & Enough work space for my needs & 0.843 \\
\hline & & & Medical equipment and facilities are always available to me & 0.764 \\
\hline & & & The clinic space is enough for me to see patients & 0.694 \\
\hline & & & The number of doctors is enough to arrange among departments & 0.652 \\
\hline & & & There are enough staff to support me during the medical examination and treatment & 0.615 \\
\hline \multirow{4}{*}{ Income } & \multirow{4}{*}{0.876} & \multirow{4}{*}{0.715} & I make enough money to make provision for my children and their future education & 0.851 \\
\hline & & & You are satisfied with the welfare regime of your hospital & 0.81 \\
\hline & & & Current income is consistent with personal devotion & 0.782 \\
\hline & & & Method of payment is based on job position assigned & 0.745 \\
\hline \multirow{4}{*}{$\begin{array}{c}\text { Quality of medical ex- } \\
\text { amination and treat- } \\
\text { ment }\end{array}$} & \multirow{4}{*}{0.861} & \multirow{4}{*}{0.687} & The professional quality of the hospital doctor is very good & 0.82 \\
\hline & & & The equipment is in good conditions & 0.786 \\
\hline & & & Medical doctors often receive feedback on treatment results & 0.75 \\
\hline & & & $\begin{array}{l}\text { When a doctor gives their opinion on improving the quality of medical examination, the doctor's } \\
\text { opinion is considered and attended to }\end{array}$ & 0.682 \\
\hline \multirow{3}{*}{$\begin{array}{l}\text { Electronic medical } \\
\text { records }\end{array}$} & \multirow{3}{*}{0.831} & \multirow{3}{*}{0.665} & Electronic healthcare system improves examination and treatment & 0.888 \\
\hline & & & Electronic healthcare interferes in the process of medical examination and treatment & 0.724 \\
\hline & & & Accessing patient information on electronic medical records is slow & 0.679 \\
\hline \multirow{3}{*}{ Autonomy at work } & \multirow{3}{*}{0.839} & \multirow{3}{*}{0.689} & I was assigned the medical examination and treatment with the right professional training & 0.82 \\
\hline & & & I can make decisions that affect patient healthcare & 0.8 \\
\hline & & & External supervisors too often question and evaluate my expertise & 0.745 \\
\hline \multirow{4}{*}{ Job satisfaction } & \multirow{4}{*}{0.908} & \multirow{4}{*}{0.744} & This hospital is the best place for me to work & 0.886 \\
\hline & & & I regard this hospital as a second house & 0.873 \\
\hline & & & I am glad to have chosen this hospital to work & 0.836 \\
\hline & & & Overall, I feel satisfied working here & 0.785 \\
\hline \multirow{4}{*}{ Organizational loyalty } & \multirow{4}{*}{0.867} & \multirow{4}{*}{0.688} & I want to stay and work at this hospital until I retire & 0.816 \\
\hline & & & I will stay to work at this hospital even though others offer more attractive salaries & 0.803 \\
\hline & & & I always work hard for this hospital & 0.782 \\
\hline & & & I was always loyal to the hospital I was working on & 0.749 \\
\hline & & & Eigenvalue & $\begin{array}{c}1.018 \\
63.399\end{array}$ \\
\hline
\end{tabular}

After analyzing the Cronbach's Alpha reliability coefficients, the convergence value of the measurement scale was assessed by Explanatory Factor Analysis (EFA) method (Giao, Vuong, \& Quan, 2020). Bartlett's test shows that sig $=0.000$; KMO coefficient is 0.847 (between 0.5 and 1), and the observed variables demonstrated an overall correlation with each other, thus confirming the appropriateness of EFA. The results of EFA with Principal Axis Factoring and rotation Promax (Oblique) have extracted 9 factors from 37 observed variables with a cumulative variance of $63.399 \%$ (pass the threshold of 50\%). Besides, the loading of all observed variables was greater than 0.5 (Table 2). Consequently, the structures have achieved convergence values (Vuong \& Giao, 2020). The results of CFA after considering the correlation among observed variable errors show that the model has 593 degrees of freedom, Chi-squared is 922.371; PClose $=0.550>0.000 ; \mathrm{CFI}=0.934$ (CFI $>0.9)$; Chi-squared / df = 1.555; RMSEA = 0.049 (CMIN / df <3, RMSEA <0.08), all indicators were satisfactory (Giao \& Vuong, 2020; Giao, Vuong, \& Tung, 2020). Therefore, the model was suitable for the survey data.

Table 2

Discriminant validity of measurement scale

\begin{tabular}{|c|c|c|c|c|c|c|c|c|c|c|}
\hline & AVE & RFD & TPO & IN & HR & QMET & OL & JS & AW & EMR \\
\hline RFD & 0.637 & 0.798 & & & & & & & & \\
\hline TPO & 0.653 & 0.019 & 0.808 & & & & & & & \\
\hline IN & 0.641 & $0.302 * * *$ & -0.071 & 0.8 & & & & & & \\
\hline HR & 0.619 & $0.416^{* * *}$ & -0.028 & $0.289 * * *$ & 0.787 & & & & & \\
\hline QMET & 0.609 & $0.540 * * *$ & 0.07 & $0.341 * * *$ & $0.440 * * *$ & 0.78 & & & & \\
\hline OL & 0.62 & $0.424 * * *$ & -0.036 & $0.200^{*}$ & $0.769 * * *$ & $0.310 * * *$ & 0.788 & & & \\
\hline JS & 0.716 & $0.596 * * *$ & 0.1 & $0.573 * * *$ & $0.487 * * *$ & $0.583 * * *$ & $0.318 * * *$ & 0.846 & & \\
\hline $\mathbf{A W}$ & 0.634 & $0.454 * * *$ & -0.012 & $0.392 * * *$ & $0.467 * * *$ & $0.409 * * *$ & $0.396^{* * *}$ & $0.565^{* * *}$ & 0.796 & \\
\hline EMR & 0.624 & $0.369 * * *$ & -0.113 & $0.392 * * *$ & $0.501 * * *$ & $0.359 * * *$ & $0.368 * * *$ & $0.489^{* * *}$ & $0.501 * * *$ & 0.79 \\
\hline
\end{tabular}

$\overline{\mathrm{AVE}}=$ Average Variance Extracted; IN = Income; RFD = Relationship with Fellow Doctors; QMET = Quality of medical examination and treatment; HR

= Hospital resources; AW = Autonomy at work; TPO = Training and promotion opportunities; EMR = Electronic medical records; JS = Job satisfaction; OL

= Organizational loyalty 
Vuong, Hieu, et al. (2020) argue that constructs achieve discriminatory values when the square root of AVE is greater than the correlation coefficient between variables. Table 3 showed that the square roots of AVE (the value in bold on the diagonal) were greater than the correlation coefficient among the constructs in its row and column. Thus, the scale has reached the discriminant validity.

\subsection{Structural Equation Modeling (SEM)}

The results of analyzing the relationships among the constructs in the model presented in Table 4 showed that most of the relationships were statistically significant with a 95\% confidence level (p-value $<0.05$ ). However, only the impact of Electronic Medical Records (EMR) on Job Satisfaction (JS) was not statistically significant at 95\% (p-value =0.194).

Table 4

Hypothesis testing results

\begin{tabular}{lclccc} 
& \multicolumn{1}{c}{ Hypothesis } & Estimates & Standard Deviation & p-value \\
\hline JS & $\leftarrow$ & RFD & 0.194 & 0.051 & 0.000 \\
JS & $\leftarrow$ & TPO & 0.091 & 0.039 & 0.019 \\
JS & $\leftarrow$ & HR & 0.119 & 0.071 & 0.005 \\
JS & $\leftarrow$ & IN & 0.264 & 0.052 & 0.000 \\
JS & $\leftarrow$ & QMET & 0.152 & 0.054 & 0.005 \\
JS & $\leftarrow$ & AW & 0.113 & 0.048 & 0.019 \\
JS & $\leftarrow$ & EMR & 0.080 & 0.061 & 0.194 \\
LTT & $\leftarrow$ & JS & 0.278 & 0.057 & 0.000 \\
\hline
\end{tabular}

The standardized results of the structural equation modeling (SEM) showed that there were 06 positive impact factors on job satisfaction in descending order as follows: Income $(\beta=0.261)$; Relationship with Fellow Doctors $(\beta=0.194)$; Quality of medical examination and treatment $(\beta=0.152)$; Hospital resources $(\beta=0.111)$; Autonomy at work $(\beta=0.1113)$; and Training and promotion opportunities $(\beta=0.091)$. Besides, Job satisfaction had a positive impact on organizational loyalty $(\beta=0.278)$.

\section{Conclusion and policy implications}

\subsection{Conclusion}

This research has explored the factors affecting job satisfaction and organizational loyalty of medical doctors in public hospitals in Vietnam. The entire measurement scales used in the study were reliable with Cronbach's Alpha coefficient greater than 0.7. This research demonstrated six factors affecting job satisfaction of medical doctors in descending order as follows: Income, Relationship with Fellow Doctors, Quality of Medical Examination and Treatment, Hospital Resources, Autonomy at Work, Training and Promotion Opportunities. Consequently, Job Satisfaction positively impacts Organizational Loyalty of medical doctors in public hospitals in Vietnam.

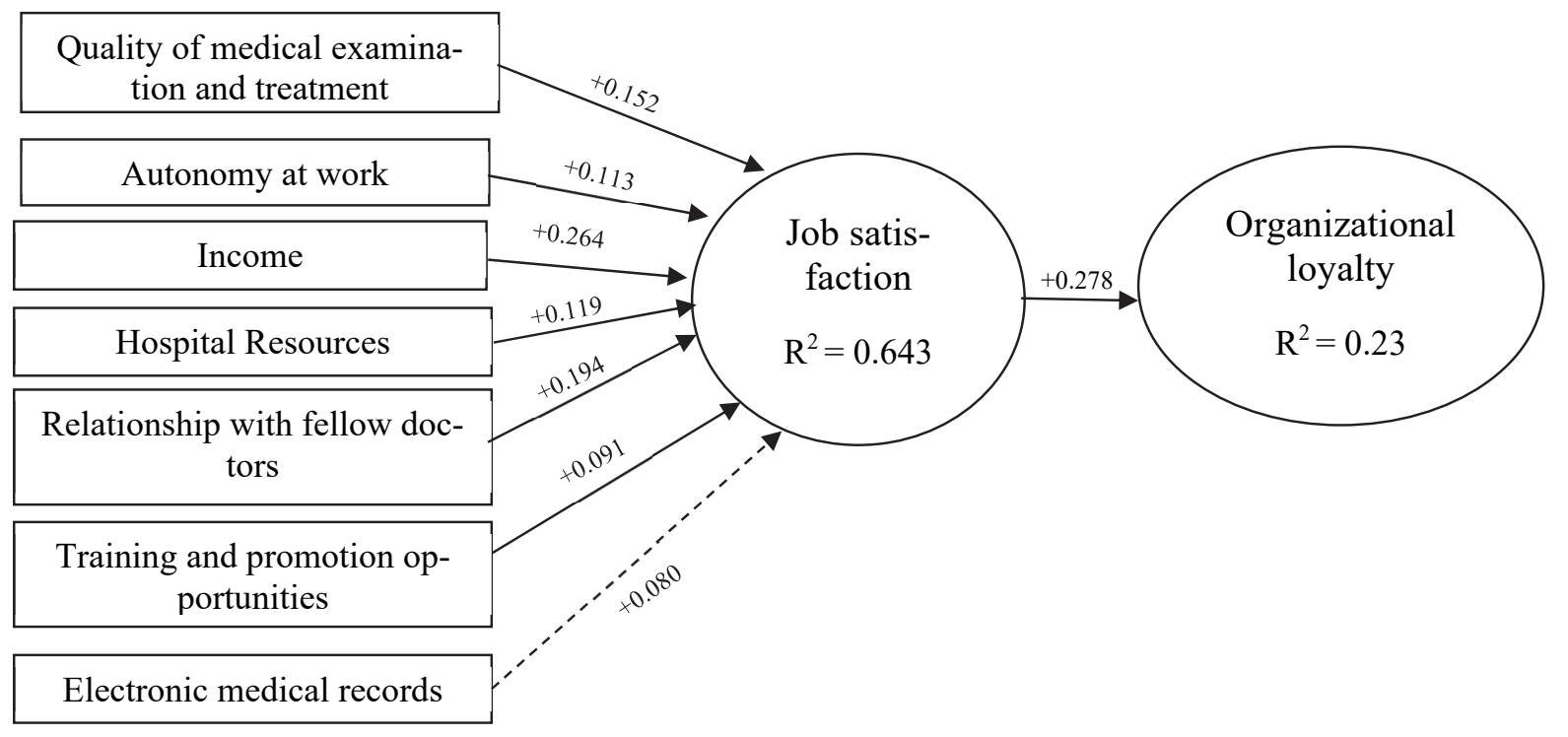

Fig. 4. The estimated results of the research model 


\subsubsection{Income}

"Income" imposes the biggest impact on job satisfaction. To enhance job satisfaction and organizational loyalty of medical doctors in public hospitals, it is necessary to devise solutions making them happy at work through the income factor. Therefore, the author proposes some policy implications. Firstly, healthcare facilities and community centers need to develop a compensation policy based on the achievements of doctors by developing incentive criteria such as reduction of the death rate of serious illnesses, reduction of hospital cross-infection, and reduction of the number of prescriptions and medical records paid by health insurance. Public healthcare centers should establish certain reward points for each criterion. When medical doctors adhere to the criteria and take action to realize the goals, the incentive compensation will be rewarded at the end of each month to increase the doctor's income.

Secondly, it is necessary to develop a clear reward system for the outstanding studies of medical doctors, or contributions that bring in new technologies in the diagnosis and successful treatment of serious clinical cases. Thirdly, it is necessary to promote medical socialization to raise funds for investing in high-tech medical equipment in the field of diagnosis and treatment to improve the quality of medical examination and treatment for patients and increase revenues from on-demand and high-quality medical services. These are also an important source of income for medical doctors. Finally, it is necessary to increase the general benefits for medical doctors and their relatives so that the doctors can focus entirely on performing duties in public hospitals.

\subsubsection{Relationship with fellow doctors}

"Relationship with fellow doctors" is the second-largest impact on job satisfaction. Firstly, hospitals and healthcare centers should set up working regulations to create an environment that emphasizes the coordination and mutual assistance of medical doctors in different units and departments. Secondly, employers should develop a code of conduct among employees so that daily communication activities are standardized, through which employees will respect and trust each other at work. Finally, interaction activities should be carried out to enhance mutual understanding among employees through picnic, tourism, and art activities programs. These approaches will create a close relationship with medical doctors in an organization.

\subsubsection{Quality of medical examination and treatment}

"Quality of medical examination and treatment" is the third-largest impact on job satisfaction. Firstly, hospitals and healthcare centers should devise adequate compensation plans for senior doctors based on graduate records, working experience, and professional credits. Secondly, the Provincial People's Committee should allocate funding to invest in adequate medical equipment according to the list of medical equipment issued by the Ministry of Health to serve the diagnosis and treatment. The municipal government should also apply various processes of socialization in the investment of high-tech medical equipment and supplies for medical doctors to improve the quality of medical examination and treatment. In this way, more patients will be attracted to public high-quality healthcare centers. Finally, the hospital leaders, heads, and chiefs should organize the coordination and consultation among medical doctors from different departments to exchange experiences in diagnosis and treatment.

\subsubsection{Hospital Resources}

"Hospital resources" is the fourth largest impact on job satisfaction. To enhance job satisfaction and organizational loyalty of medical doctors in public hospitals, it is necessary to devise solutions making them happy at work through the hospital resources. Firstly, hospitals and healthcare centers need to invest in working facilities and key equipment for capable departments on the basis of specialization. Foreign medical aids and projects are also beneficial to invest in working facilities and equipment for district hospitals and smaller-scale community healthcare centers. Secondly, leaders of hospitals and healthcare centers should regularly contact, share, and conduct professional dialogues with medical doctors to create general inspiration in professional activities. Administrators and managers should also pay close attention to equipment and working conditions that directly serve the medical diagnosis, examination, and treatment activities. Managerial responsibility would contribute to a common consensus among the team of doctors that helps to reduce unnecessary pressures which may cause negative effects on the general professional activities. Thirdly, cooperation among different hospitals should be considered seriously to enlist and share human resources and facilities, transfer and support new therapeutic techniques, and surgical methods to improve the efficiency of medical doctors. Finally, the public hospitals should develop a plan for training and developing specialized expertise for medical doctors according to the treatment system, treatment level, as well as specialties to enable doctors to improve their professional qualifications and adapt to various healthcare requirements. Medical doctors in Vietnam should be encouraged to study abroad with have appropriate policies to support schooling and create motivation in learning to improve doctors' professional qualifications. Skilled and talented medical doctors should be stimulated to make their own professional decisions and given the opportunity to assert themselves. 


\subsubsection{Autonomy at work}

"Autonomy at work" is the fifth major impact on job satisfaction. To enhance job satisfaction and organizational loyalty of medical doctors in public hospitals, it is necessary to devise solutions making them happy at work through autonomy at work. Firstly, it is necessary to enhance the rights of medical doctors in professional activities in accordance with the laws and regulations of the healthcare sector. Through clear assignment and decentralization of authority and responsibility associated with the qualifications and competencies of medical doctors, this process can foster the initiative, creativity, and promotion of professional competencies to contribute to the overall performance. Secondly, it is necessary to strengthen the inspection and supervision over the implementation of the rights and obligations of doctors in hospitals and healthcare centers in district, town, and city levels to promptly detect and rectify existing limits and lack of control. The rights and interests of the doctors should be ensured by the provisions of the governmental and general regulations. Finally, the responsibility of medical doctors should be assigned according to their specialized training and specialized experiences. Physician's prescriptions should not be restricted by the List of Drugs prescribed by Health Insurance.

\subsubsection{Training and promotion opportunities}

“Training and promotion opportunities" have the weakest impact on job satisfaction. However, to enhance job satisfaction and organizational loyalty of medical doctors in public hospitals, it is also necessary to devise solutions making them happy at work through training and promotion opportunities. Firstly, it is advisable to encourage physicians to enroll in continuous education, such as specialty training courses, to improve their qualifications and update new knowledge on medical examination and treatment activities. Secondly, hospitals and healthcare centers should build evaluation criteria to assess the performance of medical doctors to ensure objectivity and suitability to the practical conditions of each department. Performance criteria are the basis for compensation policy and other professional appointments and promotions. Finally, it is necessary to encourage physicians to participate in international conferences to exchange knowledge and experience with colleagues around the world in many different specialties and professions. This will help medical doctors explore a lot of interesting aspects of the work they are doing and build up their dedication to working for the organization.

\section{Limitations and suggestions to future studies}

Although this research has met its prescribed objective of exploring factors affecting the job satisfaction and organizational loyalty of medical doctors at public hospitals in Vietnam, there are some limitations persisted. Firstly, the study was conducted only with medical doctors who are working in public hospitals using convenient sampling methods. Therefore, the results of this research may not be highly representative of the whole population of medical doctors in Vietnam. Further research should use the probabilistic sampling method to increase the representativeness of the study. Secondly, this study only explained $64.3 \%$ of the variation in job satisfaction by the variation of 06 independent variables. Besides, only $23 \%$ of the variation in doctors' loyalty was explained by job satisfaction. The results implied that there are many other factors that affect the job satisfaction and organizational loyalty of medical doctors that this research has not yet explored. Consequently, further studies should employee more in-depth qualitative research to be able to search for more factors affecting the doctor's loyalty and job satisfaction.

\section{References}

Aityan, S. K., \& Gupta, T. K. P. (2011). Challenges of employee loyalty in corporate America. Business and Economics Journal, 55, 35-47.

Buchanan, B. (1974). Building organizational commitment: The socialization of managers in work organizations. Administrative Science Quarterly, 19, 533-546.

Chang, C. C., Chiu, C. M., \& Chen, C. A. (2010). The effect of TQM practices on employee satisfaction and loyalty in government. Total Quality Management \& Business Excellence, 21(12), 1299-1314. doi:10.1080/14783363.2010.530796

Cooil, B., Keiningham, T. L., Aksoy, L., \& Hsu, M. (2007). A longitudinal analysis of customer satisfaction and share of wallet: Investigating the moderating effect of customer characteristics. Journal of Marketing, 71(1), 67-83. doi:10.1509/jmkg.71.1.67

Dessler, G. (2019). Fundamentals of Human Resource Management (5th Ed.). USA: Pearson.

Friedberg, M. W., Chen, P. G., Van Busum, K. R., Aunon, F., Pham, C., Caloyeras, J., .. Tutty, M. (2014). Factors affecting physician professional satisfaction and their implications for patient care, health systems, and health policy. Rand health quarterly, 3(4), 1-1.

Giao, H. N. K., \& Vuong, B. N. (2020). Vietnamese consumer attitudes towards smartphone advertising. The Journal of Asian Finance, Economics and Business, 7(5), 195-204. doi:https://doi.org/10.13106/jafeb.2020.vol7.no5.195

Giao, H. N. K., Vuong, B. N., Huan, D. D., Tushar, H., \& Quan, T. N. (2020). The effect of emotional intelligence on turnover intention and the moderating role of perceived organizational support: Evidence from the banking industry of Vietnam. Sustainability, 12(5), 1857. doi:https://doi.org/10.3390/su12051857

Giao, H. N. K., Vuong, B. N., \& Quan, T. N. (2020). The influence of website quality on consumer's e-loyalty through the mediating role of e-trust and e-satisfaction: An evidence from online shopping in Vietnam. Uncertain Supply Chain Management, 8(2), 351-370. doi:https://doi.org/10.5257/j.uscm.2019.11.004 
Giao, H. N. K., Vuong, B. N., \& Tung, D. D. (2020). A model of organizational culture for enhancing organizational commitment in telecom industry: Evidence from vietnam. WSEAS Transactions on Business and Economics, 17, $215-224$. doi:https://doi.org/10.37394/23207.2020.17.23

Kim, B. J., Ishikawa, H., Liu, L., Ohwa, M., Sawada, Y., Lim, H. Y., . . Cheung, C. (2018). The effects of job autonomy and job satisfaction on burnout among careworkers in long-term care settings: Policy and practice implications for Japan and South Korea. Educational Gerontology, 44(5-6), 289-300. doi:10.1080/03601277.2018.1471255

Lawrence, P. R. (1958). The changing of organizational behavior patterns: a case study of decentralization. Harvard University Graduate School of Business Administration, Division of Research: Boston.

Locke, E. A., \& Latham, G. P. (1990). Work motivation and satisfaction: Light at the end of the tunnel. Psychological Science, 1(4), 240-246. doi:10.1111/j.1467-9280.1990.tb00207.x

Mitchell, T. R., \& Lason, J. R. (1987). People in Organization: An Introduction to Organizational Behavior. New York: McGraw-Hill.

Robbins, S. P., \& Judge, T. A. (2018). Essentials of Organizational Behavior. Harlow, United Kingdom: Pearson Education Limited.

Schmidt, S. W. (2007). The relationship between satisfaction with workplace training and overall job satisfaction. Human Resource Development Quarterly, 18(4), 481-498. doi:10.1002/hrdq.1216

Spector, P. E. (1997). Job Satisfaction: Application, Assessment, Causes, and Consequences. doi:10.4135/9781452231549

Vuong, B. N., Tung, D. D ., Hoa, N. D., Chau, N, T. D., \& Tushar, H. (2020). An empirical assessment of organizational commitment and job performance: Vietnam Small and Medium-Sized Enterprises. The Journal of Asian Finance, Economics and Business, 7(6), 277-286. doi:https://doi.org/10.13106/jafeb.2020.vol7.no6.277

Vuong, B. N., \& Giao, H. N. K. (2020). The impact of perceived brand globalness on consumers' purchase intention and the moderating role of consumer ethnocentrism: An evidence from Vietnam. Journal of International Consumer Marketing, 32(1), 47-68. doi:10.1080/08961530.2019.1619115

Vuong, B. N., Hieu, V. T., \& Trang, N. T. T. (2020). An empirical analysis of mobile banking adoption in Vietnam. Gestão e Sociedade, 14(37), 3365-3393. doi:10.21171/ges.v14i37.3078

Vuong, B. N., \& Suntrayuth, S. (2020). The impact of human resource management practices on employee engagement and moderating role of gender and marital status: An evidence from the Vietnamese banking industry. Management Science Letters, 10(7), 1633-1648. doi:https://doi.org/10.5267/j.msl.2019.12.003

Wada, K., Arimatsu, M., Higashi, T., Yoshikawa, T., Oda, S., Taniguchi, H., .. Aizawa, Y. (2009). Physician job satisfaction and working conditions in Japan. Journal of occupational health psychology, 51(3), 261-266. doi:10.1539/joh.o8023

Zia ul, I., Shah Bano, B., Hussain, M., \& Asad Shah, J. (2016). The Impact of HR Practices on Job satisfaction: A Case Study of Hotel Industry in Pakistan. The Journal of Asian Finance, Economics and Business, 3(1), 43-48. doi:https://doi.org/10.13106/jafeb.2016.vol3.no1.43

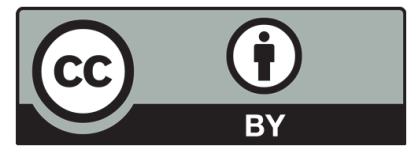

(C) 2020 by the authors; licensee Growing Science, Canada. This is an open access article distributed under the terms and conditions of the Creative Commons Attribution (CC-BY) license (http://creativecommons.org/licenses/by/4.0/). 